Please quote as: Kleinschmidt, S.; Peters, C. \& Leimeister, J. M. (2019): How to scale up contact-intensive services: ICT-enabled service innovation. In: Journal of Service Management (JOSM). 


\title{
How to scale up contact-intensive services: ICT-enabled service innovation
}

ICT-enabled service innovation

\author{
Stefan Kleinschmidt \\ Institute of Information Management, \\ University of St Gallen, St Gallen, Switzerland, and \\ Christoph Peters and Jan Marco Leimeister \\ Institute of Information Management, \\ University of St Gallen, St Gallen, Switzerland and \\ Research Center for Information System Design (ITeG), \\ University of Kassel, Kassel, Germany
}

Received 15 December 2017 Revised 30 May 2018 19 October 2018 16 April 2019 19 June 2019 Accepted 10 July 2019

\section{Abstract}

Purpose - While scaling is a viable approach to respond to growing demand, service providers in contact-intensive services (CIS) - such as education, healthcare and social services - struggle to innovate their offerings. The reason is that the scaling of CIS - unlike purely digital settings - has resource limitations. To help ease the situation, the purpose of this paper is to identify and describe the practices used in scaling CIS to support ICT-enabled service innovation.

Design/methodology/approach - The research draws on an in-depth analysis of three CIS to examine service innovation practices. The analysis informs model development for service scaling.

Findings - The analysis uncovers three practices for service scaling - service interaction analysis, service pivoting and service validation - and their related activities that are applied in a cyclic and iterative logic. Research limitations/implications - While the findings reveal that the scalability of CIS is limited and determined by the formative characteristic of personal interaction, this study and its findings describe how to leverage scalability in CIS.

Practical implications - The insights into the practices enable service providers of CIS to iteratively revise their service offerings and the logic of creating value with the service.

Originality/value - This research identifies and describes for the first time the practices for the scaling of CIS as an operationalisation of ICT-enabled service innovation.

Keywords Contact-intensive services, Service scaling practices, Service scalability, Scaling up,

Vertical scaling, Service innovation practices

Paper type Research paper

\section{Introduction}

The demand for services with high customer interaction is increasing (Buell, 2018; Glushko and Nomorosa, 2012). In fact, 85 per cent of companies predict higher levels of complexity in the interaction with customers in the upcoming years (Deloitte, 2017). This focus on personal interaction is central to contact-intensive services (CIS) that rely on personalisation, competence, and trustworthiness of employees (Patrício et al., 2008). Examples of such services exist in healthcare, education and social services; most of them improve human well-being and are therefore socially desirable (Breidbach et al., 2016). The characteristics of CIS - being labour-intensive with high personal interaction and individual service delivery (Jaakkola et al., 2017) - imply a resource intensity that constitutes a decisive factor when it comes to adapting service capacity that is relevant whether in reduction or in growth. As CIS are restricted in resources (Chase, 1981), service providers have to find new ways to innovate their services (Barras, 1986). In that regard, service innovation means the process of enhancing the service and/or the service delivery offered (Troilo et al., 2017). Service scaling is a possible operationalisation of service innovation, which refers to the ability of service providers to adapt

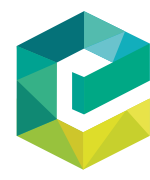

Journal of Service Managemen (C) Emerald Publishing Limited DOI 10.1108/JOSM-12-2017-0349 
service capacity (Di Pietro et al., 2018) and is particularly useful given the aforementioned resource intensity and resource restriction of CIS. This service scaling is often enabled by information and communications technology (ICT) (Lewis et al., 2011).

Unfortunately, most providers of CIS do not have specific knowledge of service scaling or ICT-enabled service innovation because the "[service] innovation process is still deeply rooted in a non-digital past" (Troilo et al., 2017, p. 617). Consequently, the details of how to implement and realise ICT-enabled service innovation remain unclear (Nambisan et al., 2017). Furthermore, to date, the design mechanisms of service scaling have been analysed and presented only in an abstract form (Huang et al., 2017) and are specific to the type of service (Jaakkola et al., 2017). In the scaling of CIS with ICT components, personal interaction - the core of CIS - needs to be reconfigured to enhance the service (Huang et al., 2017). This reconfiguration for a changed capacity may include the adaptation of current value creation for the customer and the value capturing logic for the service provider (Jin Zhang et al., 2015; Täuscher and Abdelkafi, 2018). The service scaling is carried out in specific activities that are part of service innovation practices (Droege et al., 2009; den Hertog et al., 2010; Skålén et al., 2015). An example of such an innovation practice is the recombination of resources (Beverungen et al., 2018). However, researchers currently lack a deep understanding of the interrelationship between service innovation and scaling (Jin Zhang et al., 2015), which is crucial for service scalability.

Despite the high relevance of CIS, understanding continues to be scarce in the literature of service innovation and the practice of how to attain service scalability. Therefore, this study aims to identify and describe practices used in service scaling for supporting ICTenabled service innovation. The specific research question $(R Q)$ is:

$R Q$. How do service providers achieve scalability of CIS?

To answer this research question, this study identifies and describes the relevant practices of service scaling found in three in-depth case studies of CIS. The findings reveal insights into the practices of scaling CIS and related activities.

The remainder of this paper proceeds as follows. The next section on related literature provides background on service innovation practices and the scaling of CIS. Afterwards, the research method - including the practice-based approach, the case-based data collection as well as the interpretive and in-depth analysis, which all build on each other - is explained to ensure the traceability of the findings. The subsequent presentation of the findings includes insights into three specific scaling practices and the service innovation process. Finally, the discussion and the conclusion indicate the value of the rich descriptions, provide implications for research and practice as well as explain the study's limitations and related avenues for future research.

\section{Related literature}

\section{Service innovation practices}

As mentioned in the introduction, service innovation means the process of enhancing the service and/or the service delivery (Troilo et al., 2017). It includes the revision of a service and the logic of earning money (Chew, 2016). The service innovation process is used to enhance intangible offerings and/or provide new or enhanced ways to deliver them (Helkkula et al., 2018; Troilo et al., 2017). Service innovations are based on a reconfiguration of new or existing resources (Beverungen et al., 2018; Lusch and Nambisan, 2015; Witell et al., 2016). While the successful realisation of a service innovation generally encompasses progress from the creative act to the commercialisation (Wooder and Baker, 2012), objectives are individual to the service providers (Witell et al., 2016, 2017). Two dimensions of service innovation performance are strategic competitive advantage and commercial success (Storey et al., 2016). The service innovation process is related to new 
service development (Papastathopoulou and Hultink, 2012) but focuses on existing offers (Witell et al., 2016). The service innovation practices included in the process are activities that improve existing resources, provide a competitive advantage and enable a better financial performance (Chen et al., 2009). Therefore, ICT represents a "critical factor underpinning all service innovation dimensions" (Troilo et al., 2017, p. 620). ICT is an enabler and resource that increases productivity and efficiency in service delivery (Barrett et al., 2015; Chen et al., 2009; den Hertog et al., 2010). Nonetheless, the details of the service innovation process remain unclear and reveal a research gap because previous studies have only observed the process on a meta-level (Nambisan et al., 2017).

Service innovation practices, the activities in the service innovation process, focus mainly on the service concept, the service processes and the customer experience (Troilo et al., 2017). These key aspects of service innovation are related to a broader view of service design (Patrício et al., 2011) and are expressed in the usage of methods and tools from service design (Leimeister, 2019). In the service concept, the service provider defines the "customer needs to be satisfied, how they are to be satisfied, what is to be done for the customer, and how this is to be achieved" (Goldstein et al., 2002, p. 123). The "what" of the service is the value proposition that communicates "a superior value package to targeted customers" (Payne et al., 2017, p. 472). The specification of this value proposition should be explicit, granular and focussed (Skålén et al., 2015). The service processes and delivery relate to the "how" and are revised according to the service concept (Bitner et al., 2008; Helkkula et al., 2018). These revisions influence the interfaces between customers and service providers (Teixeira et al., 2012). Lastly, the outcome of service innovation is linked to the service experience (Patrício et al., 2011) and, thus, is related to the interaction between provider and customer that occurs within the service (Helkkula et al., 2018; Leimeister, 2014). Thereby, the service experience focuses on the outcomes of the interactions (Patrício et al., 2008). Despite the existence of studies concerning the service innovation process, research is still lacking an integrated view of its key aspects (service concept, service processes and customer experience) and their (inter-) relationship (Chew, 2016).

The details of the service innovation practices are of particular interest (Droege et al., 2009; den Hertog et al., 2010). Unlike practices in service design and new service development (Yu and Sangiorgi, 2018), the content of the practices has not hitherto been reviewed (Skålén et al., 2015). Therefore, Table I provides details and definitions for the three key aspects of service innovation: service concept, service processes and customer experience.

Prototyping and feedback are accompanying constructs of all key aspects in service innovation as they aim at iteratively improving the service offered (Ojasalo and Ojasalo, 2018; Leimeister, 2019). Service prototyping is "about making services visible, to learn and communicate about services" (Blomkvist and Holmlid, 2010, p. 9). Service providers involve customers at various points for concrete ideas for improvement, feedback (Edvardsson et al., 2012; Russo-Spena and Mele, 2012) and evaluation (Meiren and Burger, 2010; Skålén et al., 2015). Service prototyping can refer to the core of the service concept on a strategic level (Meiren and Burger, 2010) or on an operational level, like the service processes (Bitner et al., 2008) and the service delivery (Chen et al., 2009). Thereby, the service interface and interaction with the customer are operational parts of the service concept (Karlsson and Skålén, 2015; Meiren and Burger, 2010). The reconfiguration of resources in service innovation is primarily directed towards the customer value as the perception of what a service is worth to a customer and/or the firm performance as improvement in competitive advantage and financial performance (Chen et al., 2014; Martelo Landroguez et al., 2013; Möller et al., 2008). Obviously, the customer value is not solely influenced by the service provider itself but increasingly by a network of different actors (Agarwal and Selen, 2011; Lusch and Nambisan, 2015). After the service innovation, the service concept should match the business concept (Agarwal and Selen, 2011) to enable improvements in firm performance (Chen et al., 2009). Thus far, detailed activities in these service innovation practices are missing (Skålén et al., 2015).
ICT-enabled service innovation 
JOSM

\begin{tabular}{|c|c|c|c|}
\hline Key aspect & Description & Activity & Key reference(s) \\
\hline \multirow[t]{2}{*}{ Service concept } & \multirow{2}{*}{$\begin{array}{l}\text { The representation of the service and } \\
\text { value capturing logic including the } \\
\text { value proposition, form and function } \\
\text { of the service offering, and outcome/ } \\
\text { problem solution to the customer }\end{array}$} & $\begin{array}{l}\text { Refining the value } \\
\text { creation for the } \\
\text { customer }\end{array}$ & $\begin{array}{l}\text { Meiren and Burger } \\
\text { (2010); Ojasalo and } \\
\text { Ojasalo (2018); Skålén } \\
\text { et al. (2015) }\end{array}$ \\
\hline & & $\begin{array}{l}\text { Refining the value } \\
\text { capture for the } \\
\text { service provider }\end{array}$ & $\begin{array}{l}\text { Chen et al. (2014); Martelo } \\
\text { Landroguez et al. (2013); } \\
\text { Möller } \text { et al. (2008) }\end{array}$ \\
\hline Service processes & $\begin{array}{l}\text { The representation of the service } \\
\text { delivery system that creates value for } \\
\text { the customer in the service offering; } \\
\text { includes internal and external resources }\end{array}$ & $\begin{array}{l}\text { (Re-)planning the } \\
\text { service delivery } \\
\text { Integrating } \\
\text { external } \\
\text { participants in } \\
\text { service delivery }\end{array}$ & $\begin{array}{l}\text { Bitner et al. (2008); Chen } \\
\text { et al. (2009); Voss and } \\
\text { Hsuan (2009) } \\
\text { Agarwal and Selen } \\
\text { (2011); Lusch and } \\
\text { Nambisan (2015) }\end{array}$ \\
\hline \multirow[t]{2}{*}{ Customer experience } & \multirow{2}{*}{$\begin{array}{l}\text { The representation of the interaction } \\
\text { between the service provider and the } \\
\text { customer; includes (infra-) structure } \\
\text { and customer integration, and } \\
\text { customer touch points }\end{array}$} & $\begin{array}{l}\text { Revising service } \\
\text { encounter and } \\
\text { interface }\end{array}$ & $\begin{array}{l}\text { Karlsson and Skålén } \\
\text { (2015); Meuter } \text { et al. (2000) }\end{array}$ \\
\hline & & $\begin{array}{l}\text { Revising } \\
\text { customer } \\
\text { integration }\end{array}$ & $\begin{array}{l}\text { Edvardsson } \text { et al. (2012); } \\
\text { Russo-Spena and Mele } \\
\text { (2012) }\end{array}$ \\
\hline
\end{tabular}

\section{Scaling of CIS}

If a service provider is unable to cope with the growing number of inquiries, as it is the case in CIS such as healthcare, education and social services, either not all customers will be served or the quality of service will decrease (Zhao and Di Benedetto, 2013). Neither case is desirable for the company or the customer. Service scaling means the flexible adaptation of service resources to meet the needed capacity. Scalability is a (mainly technical) design characteristic of systems, networks or processes when adapting to growing volumes (Bondi, 2000; Hill, 1990). Service providers have the option to use vertical or horizontal scaling for influencing the characteristic of scalability in their services. In horizontal scaling, new resources are added to increase the capacity of the service. In the context of CIS, those new resources predominantly include investments in new personnel (Chase, 1981). In vertical scaling, the existing service personnel are enabled by adding resources to adapt to the capacity. Complete scaling of a business requires three activities: outsourcing of high-cost tasks, providing self-customised value propositions to users and enabling a flexible adaptation of value creation capacity for the customer through modular design (Täuscher and Abdelkafi, 2018). While different examples of service scalability can be found in the literature for digital settings - such as scaling infrastructure (Lewis et al., 2011) or scaling of the user base (Huang et al., 2017) - there is a lack of operationalisation on ICT-enabled service innovation and scaling of CIS involving personal interaction (Leimeister, 2014).

The way CIS create value impedes the use of horizontal scaling, because CIS are "customized services that are labor-intensive with high customer interaction in service delivery" (Jaakkola et al., 2017, p. 337). These services entail a high degree of contact intensity with personal interaction between service providers and their customers (Teixeira et al., 2017). Thus, these services include customer value as value-in-exchange which means that the value is uniquely and phenomenologically determined by the customer (Martelo Landroguez et al., 2013). The innovation of CIS presents a challenge for service providers. On the one hand, the high degree of contact intensity in these services 
determine the value creation for the customer and limit the innovation capability (Jaakkola et al., 2017; Vargo and Lusch, 2016). This includes the limitation of resources because employees can serve only a fixed number of customers (usually one) at a time and the individuality is a necessary condition in the value creation for the customer (Chase, 1981). On the other hand, the service capacity is difficult to adapt when the demand changes because service personnel as resources are limited and not divisible. Hence, a difference between digital settings - such as cloud services - as the origin of scaling and the scalability and CIS exists where marginal costs are significantly higher (Huang et al., 2017). Additionally, a strong interdependence between the organisational context and the ICT in service companies exists (Storey et al., 2016; Troilo et al., 2017). Personal interaction can rarely be outsourced (Jin Zhang et al., 2015). Generally, extension via horizontal scaling is associated with difficulties because of restrictions in resources such as service personnel (Witell et al., 2017). Vertical scaling can be realised with existing service personnel. Therefore, vertical scaling is the preferred option in CIS (Barrett et al., 2015) and is used synonymously with the term "scaling". Given the high interdependence between the organisational context and the ICT in companies providing CIS, understanding design restrictions is crucial for scalability. However, as of now, vertical scaling as the preferred option in CIS and the understanding of design restrictions is an under-researched topic.

\section{Research method}

Research objective

The objective of this study is to identify and describe the practices used in scaling CIS and thereby to support service providers in ICT-enabled service innovation. This requires an in-depth analysis of the scaling activities and their context (Schatzki, 2001). To do so, this study draws on a practice lens that is mainly used in social sciences and sociology (Feldman and Orlikowski, 2011). However, the practice approach is not unified (Feldman and Orlikowski, 2011; Nicolini, 2009), but practices can be understood as "embodied, materially mediated arrays of human activity centrally organised around shared practical understanding" (Schatzki, 2001, p. 11). Therefore, this understanding is used as a working definition of practices. Its inherent "arrays of human activity" as well as their corresponding context can help to inform theory and practice (Feldman and Orlikowski, 2011). The analysis of the specific activities for scaling CIS can reveal patterns and relationships across the actions (Nicolini, 2009). To gain these insights, a practice-based lens is chosen. These insights allow for the identification, description and better understanding of concrete service innovation practices. However, the understanding of service innovation practices is still in the early stages of development (Skålén et al., 2015; Vargo and Lusch, 2016). The identification and description of concrete service innovation practices - in this study for scaling of CIS - can contribute to a better understanding of service innovation (Witell et al., 2016).

\section{Case selection}

Given that the objective of this study is to distil rich insights about service innovation practices, a qualitative research design is appropriate. A case-based setting with an interpretive and in-depth analysis (Walsham, 1995, 2006) is used. The unit of analysis is one specific CIS and its ICT-enabled scaling; this unit of analysis has been used before to understand service innovation (Russo-Spena and Mele, 2012) as well as the introduction of ICT (Orlikowski, 2000). To ensure the generalisability of this study's findings, the case selection was based on the formative characteristic of CIS (the degree of contact intensity) as a basis for comparability and the possibility of scaling and scalability (the degree of technology in the service).

\section{ICT-enabled service innovation}


The degree of contact intensity describes the extent of personal interaction in the service, which can be an indicator of the individualisation of the service delivery (Jaakkola et al., 2017). To achieve comparability of the findings, this study uses three particular CIS with a high degree of contact intensity:

- Case A is a home care service in Northern Germany that provides professional nursing to elderly people who cannot cope with everyday life. The high contact intensity of the service is reflected in the personal attention of a care worker towards a person in need of help. Thus, the service is based on intensive assistance and an entirely offline service delivery.

- Case B is a transportation service in Southern Germany that organises drivers for specific everyday trips of elderly people. The high contact intensity of the service is reflected in the trips made by drivers for citizens in need of transport. The processes of coordination include personal matchmaking between 3,800 potential customers and drivers.

- Case $\mathrm{C}$ is a matchmaking service for volunteers in Switzerland that offers volunteers everyday jobs in voluntary organisations. The matchmaking process - in which volunteers are placed in over 3,000 associations/NGOs - reflects the high contact intensity of the service. Volunteers prefer telephone consultation because of the uncertainties in the matchmaking process.

In contrast, the degree of technology reflects the level of ICT-enabled service provisioning and is an indicator of the scalability of the service (Lewis et al., 2011). The objective for each company was to scale the capacity of the service with limited resources via the implementation of a service platform that can "create value by facilitating interactions between external producers and consumers" (van Alstyne et al., 2016, p. 57). To contrast the service scaling practices and generalise the findings on CIS, the cases had different starting points and objectives varying in the degree of technology:

- Case A (low degree of technology) involves an offline service with no specific technology used. The intended service scaling should enable greater concentration of the nursing on the person seeking help by replacing individual service parts with automated ones.

- In Case B (medium degree of technology), telephone consultations are used to make the transportation service available to other citizens of the small town. The service scaling via the platform should provide an online process replacing a large part of the coordination tasks.

- In Case C (high degree of technology), the customers have the possibility to contact the voluntary organisations via the website or telephone. The service scaling includes more standardised and more simple processes that should require less personal consultation and less manual control by the employees for initiation, arrangement and coordination.

\section{Data collection}

The three cases are built on a rich set of data over a three-year period (11/2014-11/2017). In this period, all CIS were revised in the context of projects that covered the implementation of service platforms. The projects consisted of two parts: a technical part comprising the development and testing of a service platform and a business part comprising the companyindividual design of the service concept and implementation of the service processes. This data set was extended over time to allow for further analysis. Further information extended the information in the analysis. The data collection contained data from workshops with participant observation, interviews with analysis of memos and notes, project documents with document 
analysis and the development level of the ICT components. Table II provides details of the data collected in the projects and how it was used in the analysis.

Primary case data were collected in 13 project workshops via participant observations (Glaser and Strauss, 1999). The main purpose of this data collection was to directly capture the activities in scaling CIS. The participants in the workshops were the three project teams in the three different cases with the respective project leads and overall 14 project team members with industry expertise. These workshops were held during the project time to coordinate the service innovation activities and to make decisions regarding the scaling of individual services. Workshop discussion topics covered the definition of the objectives, consolidation of the analyses, requirements analyses for the services, definition of ICT components, modification of services and service concept as well as training on, analysis of, and feedback to the services. The research team was able to attend these workshops as involved researchers (Walsham, 1995) and capture detailed information about activities of the individual project teams (Feldman and Orlikowski, 2011; Nicolini, 2009) for scaling the services. Additionally, the activities in the workshops provided data that included the planning of the next steps. The observations were captured in detailed notes about the activities and enhanced with information from the workshop documentation.

The workshop data were triangulated (Gibbert et al., 2008) by informal interviews, project documents and the level of development on the platforms. Overall, 32 interviews took place with project leads and team members before and after the workshops. Although interviews have their limitations in the study of practice, the purpose of gathering these data for analysis were to capture the interpretations of the project team regarding the activities in the workshops and the context of the project setting. Therefore, the focus of the interviews was on their understanding of the project, their individual objectives, user involvement, requirements and modifications to the services, evaluation of scaling and the project achievements. Additional information determined the number of interviews for theoretical saturation (Glaser and Strauss, 1999). The findings and statements from the interviews were documented using memos and field notes. Moreover, 15 project documents provided insights into the understanding of the project members regarding the progress and the results of scaling. These documents were helpful for understanding the results regarding the service concepts, the processes, the ICT components and the business logic. The main purpose was to reflect on prior information that was communicated to external stakeholders. The rich insights from the three sources (workshops, interviews and documents) have been reflected on the level of development of the ICT components and the CIS, which were presented in the form of mock-ups and market-ready platforms.

\section{Data analysis}

The objective of the data analysis was the specification of service scaling practices and their interrelationships. Following methods of qualitative data analysis (Gioia et al., 2013; Miles et al., 2014), a two-stage approach was used: first stage, identification of service scaling practices, and second stage, detailing of the service scaling practices.

In the first stage, the analysis of the workshops and interviews enabled the identification of the service innovation practices within the cases. Methods like service blueprinting (Bitner et al., 2008) or business model design (Osterwalder and Pigneur, 2010) and decisions for service scaling were part of the respective activities. The explanations in the interviews provided more detailed insights into the context of the scaling activities such as the concrete objective to use a service blueprint. Descriptive coding of activities allowed structuring and filtering of the collected data into nine first-order concepts, see Figure 1. The concepts were labelled either by the workshop activities or the activities included in the documentation. The descriptions from
ICT-enabled service innovation 
JOSM

Table II.

Data collection methods and use in data analysis
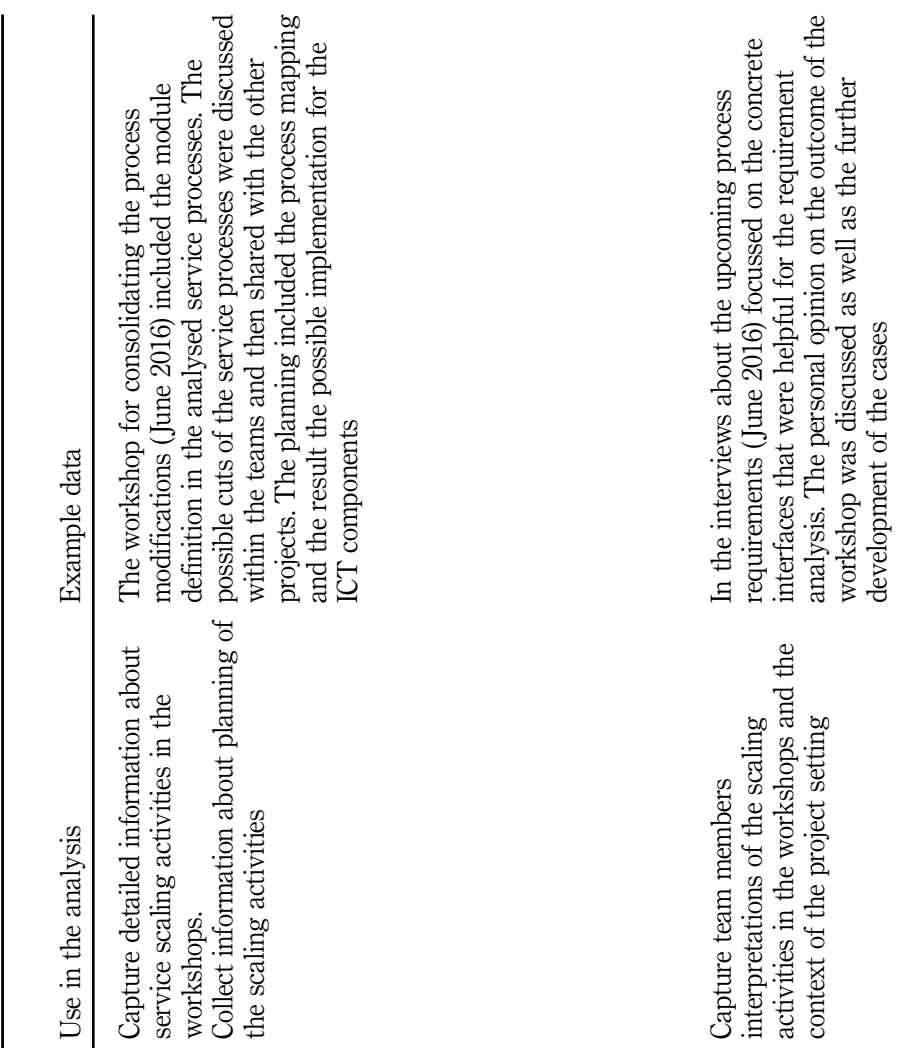

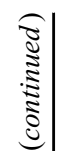

必.声苋

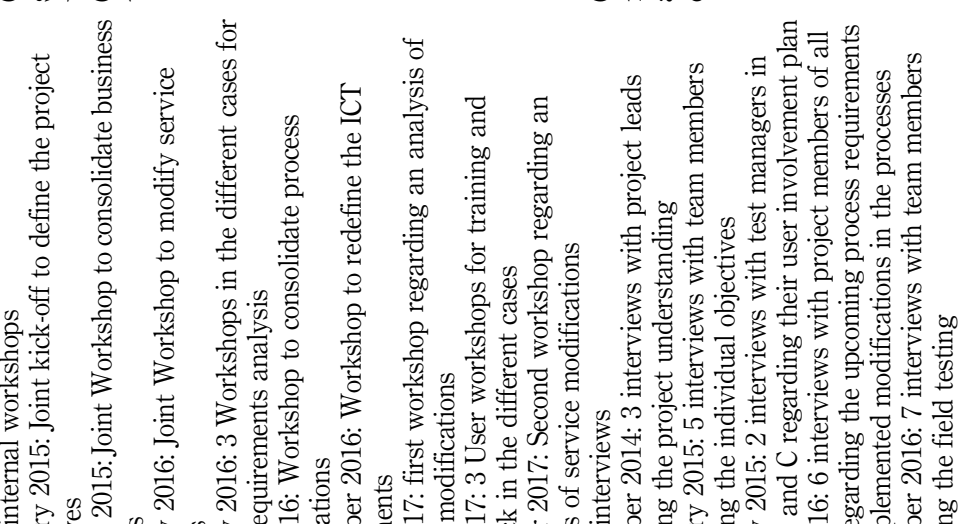

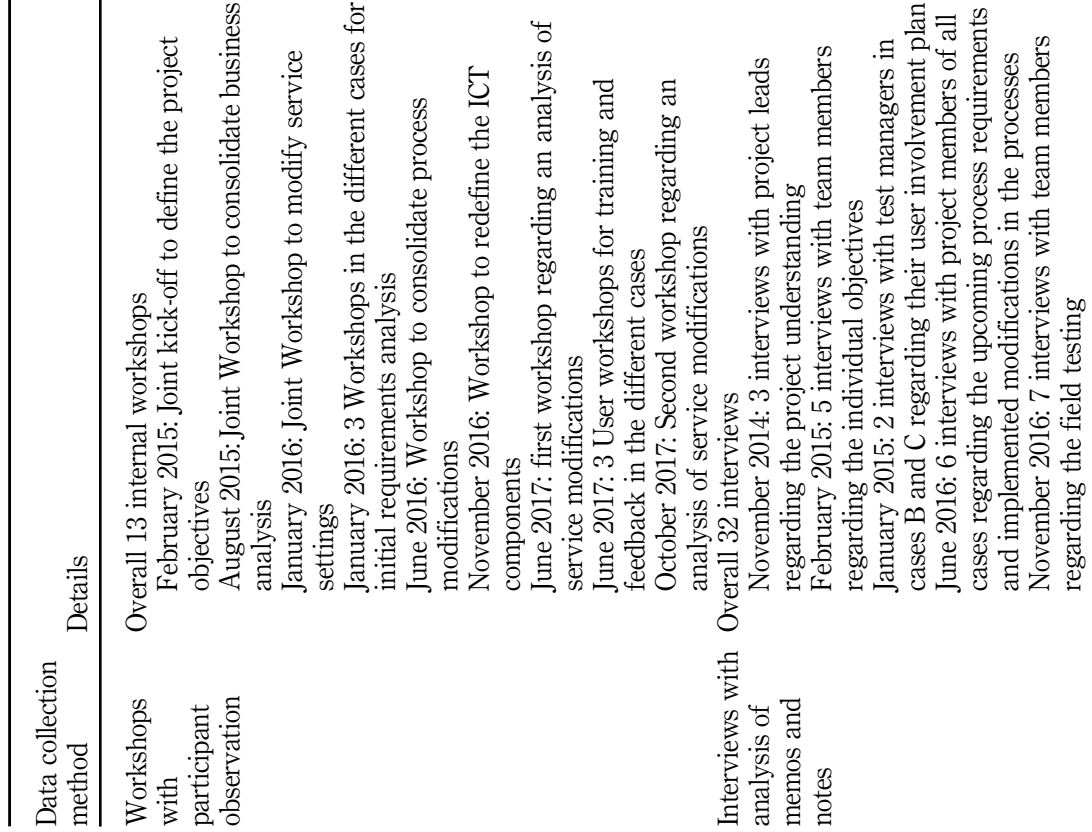

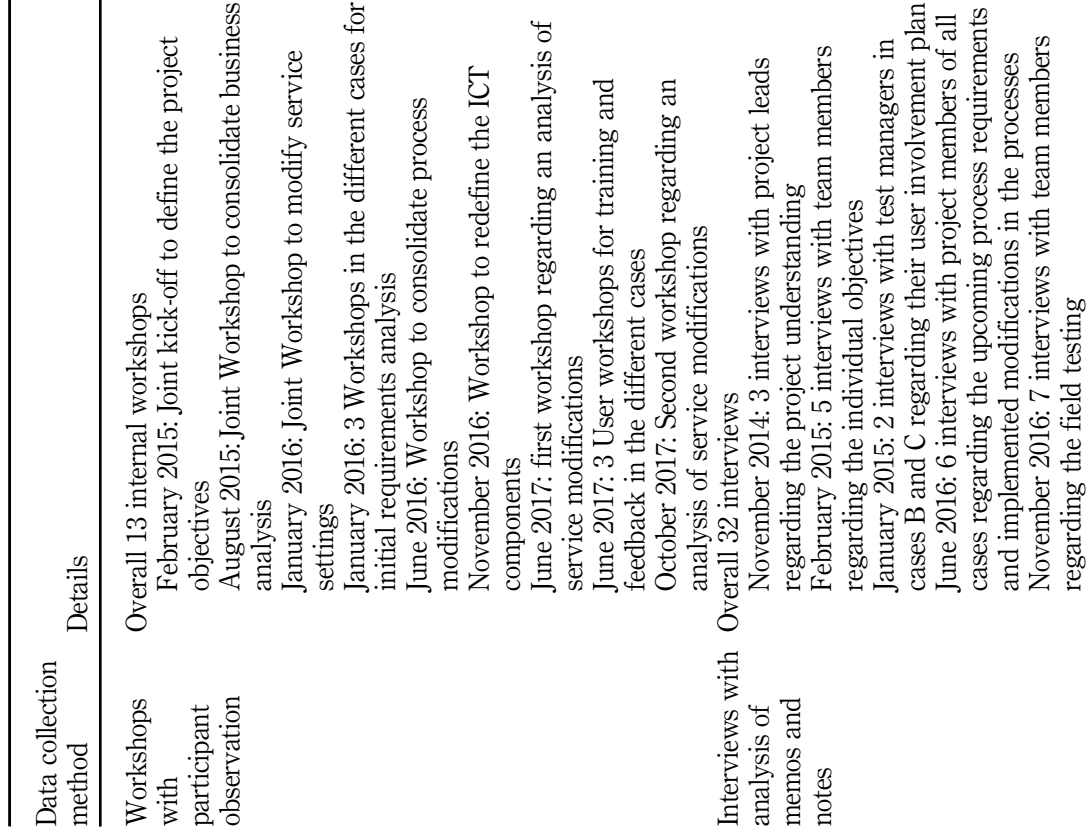







the interviews enabled the filtering of the activities regarding service scaling. This included a search for alternative influencing factors and resulted in the condensation of the concepts to the completed set of activities in scaling CIS. An aggregation of these concepts into meaningful thematic blocks structured this collection of activities. This structuring resulted in nine coded second-order themes: value definition, service specification, module definition, business modelling, process modelling, ICT component development, customer acceptance testing, field testing and value review (see Figure 1). The themes were named based on containing firstorder concepts or were specifically mentioned by the interviewees.

In the second stage, cross-case synthesis (Miles et al., 2014) revealed data similarities and differences in the three cases. A repeated alternation of perspectives between individual cases and the entire set of cases enabled the interpretation of the activities (Nicolini, 2009). These evidence-based activities were validated based on findings in related literature on service innovation. The cross-referencing of the different cases with the project documents and the level of development in the ICT-enabled service allowed the analysis of the causal relationship of the activities. Within the three cases, three repeating practices were identified: service interaction analysis (i.e. analysis of the defining parts of the CIS), service pivoting (i.e. adaptation of service concepts and processes) and service validation (i.e. testing and review of the improvement). A summary of this data structure as a first intermediate result is depicted in Figure 1. In accordance with the data-analysis objective, the overall output of the synthesis is the description of the practices (Reckwitz, 2002). Statements based on interview notes and documentation provided evidence of these findings. Moreover, the

First-Order Concepts
Second-Order

Themes
Service

Innovation

Practices



Figure 1.

Data structure 
level of development in the ICT-enabled service revealed the concrete functionality behind the intended scaling. To summarise the practices and create more detailed descriptions of the concepts of service scaling, the final insights were organised in the form of research propositions to enable model development.

ICT-enabled service innovation

\section{Findings}

The service innovation projects and the scaling of the CIS in the included cases were successful as they simplified the service processes and reduced the employees' workload. However, a project lead described the results as follows:

Thanks to the service platform, we have a more automated service. We can prove this with our performance indicators that show a higher volume of transactions. However, we still work with people that talk to each other. That's a good thing because this is the core of what we do, but it's not a fully automated process. (Project lead, Case A)

Thus, the result with the most comprehensive consequences in the cases is that the scalability of CIS is limited. This limitation is because of the peoples' involvement in the process. The characteristics of CIS and particularly the personal interaction as a source of value creation for the customers impede full scalability of these services. The service providers overcame this limitation with a specific focus on the personal interactions of the services and respective activities for improved scaling of these interactions. The following examples and excerpts from the interviews and project documents explain the individual activities of the three identified service innovation practices: service interaction analysis, service pivoting and service validation.

\section{Service interaction analysis}

At the beginning of the projects, the project teams focussed on the identification and analysis of existing structures in service interactions and on learning about the need for improvement in scaling. The review of existing structures occurred in workshop settings and included discussions about customer value, customer experience, and customer process. When it was determined in other practices for service scaling that value and processes of the service are not yet clear for revision or the customer, a new interaction analysis was carried out. Thus, the other practices constitute a feedback mechanism for the findings of the service interaction analysis. The practice of service interaction analysis was found to involve three activities: value definition, process visualisation and module definition. Furthermore, insights into the practice of service interaction analysis led to a proposition regarding the practice and scaling CIS.

Value definition. The first activity in the workshop sessions included the definition of the specific offered services by identifying their respective process starts and ends. The value proposition to customers was analysed using a value proposition canvas (Osterwalder et al., 2015) to focus on customers. Lead users that are "users whose present strong needs will become general in a marketplace" (von Hippel, 1986, p. 791) reflected on value propositions, and their reflections were used to validate the assumptions of the project teams. This reflection resulted in a current service concept that reflected the fundamental value of the service to the customer and the service provider. One of the participants of the workshop explained the impact of the initial service analysis:

In the analysis [of the service], it is critical for us to have regular feedback from important users. In the beginning, they can provide us valuable input and we can adjust the service very quickly and before investing too much. (Project lead, case B)

Service specification. The specification of the services was implemented in the workshop activities by the visualisation of the service delivery and interaction points with the 
customers. The workshop discussions centred on the process steps and the value of the interactions including the existing ICT components. Service blueprinting (Bitner et al., 2008) as a tool for process visualisation allowed in-depth discussions of the processes and existing ICT components in this process. This resulted in identifying possible impediments in the process and the variability in capacity:

First, we have to find out where the service and processes have weaknesses, where the bottleneck is, before we could start thinking about the service platform. This most often concerns personal interactions in the service. (Project team member, case C)

The service processes and the service blueprint had different characteristics and forms. For example, in cases $\mathrm{B}$ and $\mathrm{C}$, a concrete process description was created, whereas in case $\mathrm{A}$ only a basic concept was described because formal processes were not specified before.

Module definition. After the definition of the existing services and processes, the project team focussed on possibilities for modularising the service delivery within the process structures. The services were divided into logical parts that generate value on their own, e.g., the initiation of a matchmaking process in case $\mathrm{C}$. The different modules of the services were chronologically structured to provide starting points for further discussion. This structuring enabled the identification of valuable service modules including interaction with the customers. The modules were perceived as helpful by the project teams with their defined interfaces, and dedicated customer value, customer process and customer experience enabled easier reconfiguration. The team members ranked the modules where service scaling was useful based on their probability to promote or prevent scaling, which in turn was discussed in the projects with the lead users. Those involved perceived the need for action in interaction as an important "take away message" (Project lead, case C). Findings and output for the project team from this activity are potential fields of action in the service scaling:

The main objectives were to identify information deficits, end user needs, [...], analyse the shortcomings [...], and define the processes [...]. The deliverable is an input for the detailed requirements for the system architecture and development of a [service] platform. (Draft service specification)

The insights into the identification and analysis of existing structures led to the following proposition for service interaction analysis as part of scaling CIS:

P1. The scaling of CIS involves the definition and analysis of service value, processes, and structures to identify the interactions that promote or prevent scaling.

\section{Service pivoting}

In the workshops to redefine the ICT components, the teams planned the service innovation with the revision of the service concept and processes with ICT components and started the implementation of ICT-enabled services. The objective of the workshops was to conceptualise scaling in the service concept and service processes. The term service pivoting is based on the revision of startups (Ries, 2011) and was mentioned by the project lead in case C. Service pivoting aims at the revision of the service - including ICT components - to improve the service capacity and scalability. As a result of this service pivoting, the revised service concept is implemented in an ICT-enabled service that offers the intended service scaling. The workshops revealed three activities of the service pivoting practice: business modelling, process modelling and software development. Furthermore, insights gleaned from this led to a proposition regarding the service pivoting practice and scaling CIS.

Business modelling. The revision of the service concept required the definition of the scope of scaling and degree of digitisation in the service. A critical discussion in the 
workshops concerned the revision of the service concept, specifically the question of how the scaling can be implemented. For example, in case B, the focus was on the coordination of a specific driving service because it had the highest potential for scaling. The building blocks of the business model canvas (Osterwalder and Pigneur, 2010) served as starting points for the discussion of the dependencies in the service processes and modules. The integration of ICT components into the existing service parts was checked in each building block and the overall logic of the service was validated. In case A, this discussion and user feedback led to the extension of the service with components for communicating a clear value proposition, usability, and activation. The project leads ensured that service scaling was the focus of the activities. The validation of the business logic forced a revision to the developed ideas. The feedback from the customers and service employees led to a clear vision and requirements:

Involving our end users in the process of designing a usable online platform helped us to understand their issues and requirements [...]. We could discover their way of thinking and how our product could make it work better for them. (End user framework report)

Process modelling. Process configurations were developed and were iteratively improved based on feedback from customers and service employees. Automation with ICT components was planned where personal interaction was not necessary or desirable. A "satisficing" solution for the service provider consisted of an intelligent interplay of personal interaction and ICT components. In the discussion, a decisive argument for a combination of ICT and non-ICT components in case B was that its customers could use the ICT components - such as the booking of drives - without help. It was essential for the service providers that the core of the service remained stable:

The [service] platform is considered as a working tool for better organisation of [the service], documentation of processes and coordination [...] leading to higher efficiency (reduced costs) and possibly reduced workload. (Final service specification)

As a result, the process requirements for scaling of CIS were three-fold: flexibility in the service delivery, decision-making authority of service employees and use of existing data. First, the analysis revealed interactions with customers that did not add value to the flexibility of the service delivery. The requirements for automated processes allowed an individual service delivery. Second, regarding decision-making authority, the process analysis made the rigid processes evident. The requirements allowed service employees to manage the problemsolving in the service delivery and evaluate the results for new customer needs. Third, regarding using existing data, the feedback from customers regarding the ICT components implied that further data collection was considered ineffective. Therefore, the requirements included the need that existing data was used and standardised.

Software development. The individual ICT components for the service modules were developed according to the requirements of business and process modelling. For this purpose, a solution architecture was developed that technically translated the requirements into functionality. This architecture was discussed within an expanded project team with development expertise for ICT components. The focus of the discussion was on the usability of this solution architecture for the customers and the service personnel. During the actual development of the ICT components, the service prototypes were discussed with the lead users to assess whether all requirements had been included. Thereby, the implementation of documented requirements was extended with the feedback. Additionally, this development of the individual ICT components was done with service prototyping to quickly test key functionality of the services. In this service prototyping, the requirements and developments were constantly questioned and refined. The focus of the project team at the end of the first developments was a verification of the intended scaling of the service. The project team
ICT-enabled service innovation 
members mentioned that this practice exceeded the activities in the workshops and included the iterative development and requirements refinement of ICT components:

Various points of contact with end users such as interviews provide insights in their wishes and further requirements [...]. The piloting provides means to the development and provides feedback to the same.

The comments by the users provide valuable input for a [software] development. (Evaluation report)

The insights about the revision of the service concept and processes led to the following proposition for service pivoting as part of scaling CIS:

P2. The scaling of CIS involves the iterative specification, implementation, and refinement of the service regarding its business logic, its underlying processes, and software components.

\section{Service validation}

The service providers introduced the services to the market and tested the ICT-enabled service with real customers. The ICT components and services were at an advanced development stage and were described as a "minimum viable service" (Ojasalo and Ojasalo, 2018). The objective of the tests was the gathering of customer feedback regarding the implemented requirements, the functionality and usability of the ICT-enabled services and the verification of the scalability. The outcomes were opportunities for revision that enable the validation of objectives. In summary, the service validation aimed at testing and refining the market-ready service's performance and customer acceptance. The activities of the service validation practice included customer acceptance testing, field testing and value review. Furthermore, detailed study of these activities resulted in a proposition.

Customer acceptance testing. The focus of the workshops was on the validation of the scaling within a specific context. In the interviews, the project team was rather critical concerning the customers' acceptance of the ICT components. Therefore, the planning of the acceptance tests included the specification of the test purpose and test scenarios. The tests' purpose comprised the ability of ICT components to contribute to scaling in the service processes. The test scenarios were concrete applications of scaled services. After this specification of the test scenarios, functionality tests for the ICT components took place. Afterwards, the acceptance tests were started. Fundamental topics regarding usability were raised by the customers during the walkthroughs of the processes that included changes in services and ICT components. These topics were structured and prioritised according to their importance for creating customer value. For example, in case A, privacy concerns regarding the online platform came up. The focus on the specific application enabled functionality and usability testing in the service process:

The overall idea [of testing] was to start the platform with specific services for the end users and the end-user organisations. This approach quickly reveals the specific needs of the end user. (Draft business plan)

Field testing. The acceptance tests resulted in a ready-to-market ICT-enabled service. The services were tested in two rounds of field tests for each of the three cases. The first round aimed at ensuring that the functionality and practicality for customers and employees supported daily business. The project team reported that the testing resulted in feedback that improved the quality of the service. This feedback included improvement suggestions to the user interface and the lead time of services. The project team continued to test the scaling of the service in the second round in a revised form. This time, the users were trained intensively in dealing with ICT components. The results of the cases revealed that the revision of the CIS depended on the interaction of ICT and non-ICT components. The combination of personal interaction and ICT components interacted in such a way that 
scaling did not disrupt the processes but rather allowed employees more personal interaction. The interactions were thoroughly reviewed and emerging improvements were documented for further development. In these improvements, the real customer processes served as orientation:

The business logic [of the service platform] was well-tested and improved to meet the highest market standards. The time $[\ldots]$ was devoted to refining the already tested solutions. (Testing report)

Value review. The decisive factor for further actions was whether more customers can be or have been served while providing the same service quality. Therefore, the activities within the project team focussed primarily on measuring service performance. The result of the field tests was the proof-of-concept for the service scaling improvement. The three cases included an improved flow of customers through the processes. In case A, the first-time introduction of ICT components revealed the greatest effects on customer involvement. Other than service performance, the project team focussed on the logic of the service concept. This includes the integration of the ICT components and the modular design in the value creation for the customer. The project team reported that the value logic of the CIS adapted slowly because of the familiar personal interaction. Therefore, in the transportation service (case B), both service processes - old and new - ran parallel during the transition period. When the scalability and consistency of the CIS could be verfied, the development and revision of the CIS was started again as soon as the service demand reached a critical level. The validation could lead to a rejection of the ICT-enabled service, which resulted in a further revision in the service pivoting or further analysis via the service interaction analysis:

The [services] went through a couple of interesting developments within the course of the project. Starting from a very vast offer of services on the platform, [a specific service] was soon recognised to be the most interesting service to focus on. (Final project report)

The insights about introduction of the services to the market led to the following proposition for service validation as part of scaling CIS:

P3. The scaling of CIS involves the testing and evaluation of functionality, acceptance, usability, and practicality of the market-ready service.

\section{Model development}

The identified practices for service scaling are service interaction analysis, service pivoting and service validation. These practices enabled the service providers to revise their CIS to increase scalability. The increase in scalability is manifested by the flexible adaptation of service resources:

[The services] provide [the users] with easy-to-use ICT-supported solutions. In doing so, the [service platform] project increases transparency of demands and offerings, allowing for flexible and selfdetermined participation. (Evaluation report)

The practice of service interaction analysis was the entry point to service scaling. In this practice, service providers clarified which parts of the service are high in personal interaction and thereby which parts promote and prevent service scaling. Furthermore, the practice includes identifying which modules of the service can be supported with ICT while ensuring the same or an even higher customer value.

The service pivoting practice improved the service capacity by adapting the service concept, the processes and structure of the service. The focus of the improvement was in the ICT-enabled service as being a materialisation of the service innovation. The adjustments were based on customer value creation possibilities of the resource reconfiguration. The important coordination occurred in the interfaces between personal interaction and ICT.
ICT-enabled service innovation

\section{$+$}


Once the service adjustment was ready for the market, the service provider and the customer tested it via the practice of service validation. This practice includes checking whether the service is more efficient than before and making modifications to ensure that it is. The activities in the workshops illustrated, however, that service scaling is centred around increasing value for customers and service providers. Feedback and iteration in the individual activities of the service scaling practices and the return to the previous activities are an integral part of the procedure:

Applying an agile approach and involving the user on a regular basis as well as automated deployment and testing allowed to deliver and improve an integrated solution step by step. (Final project report)

These insights led to the following proposition regarding the interrelationship of practices in the scaling of CIS:

P4. The scaling of contact-intensive service involves a cyclic and iterative process of practices that aim at responding flexibly to changing demand and improving value for the users and service providers.

Figure 2 summarises this relationship between the three practices and the nine activities, depicting the cyclic innovations logic in a service scaling concept.

\section{Discussion}

\section{Theoretical contribution}

This study identifies and describes for the first time the three practices for scaling CIS: service interaction analysis, service pivoting and service validation. In contrast to existing research, these practices provide details of the service innovation process that have hitherto been considered only on a meta-level. The practices cover a cyclic and iterative process including the following (summary of the propositions): the definition and analysis of service value, processes and structures; the iterative specification, implementation and refinement of business logic, underlying processes and software components; and the testing and evaluation of functionality, acceptance, usability and practicality.

The insights on service interaction analysis offer details about the operant resources that previously have been considered as input for the service innovation practices (Chen et al., 2009). In detail, the analysis was identified as practice itself that serves as a prerequisite to determine problems with volume and scalability. In this context, the interaction between customer and service provider was considered as the focus of scaling. The outcome of the analysis includes defined customer value, customer process and customer experience that enable the identification of service modules and operationalise the findings of Täuscher and Abdelkafi (2018) on modular business design. Thus, the value definition, the process visualisation and the module definition are an extension of the innovation process.

Furthermore, the insights on service pivoting complement the discussion on ICT-enabled service innovation (den Hertog et al., 2010; Troilo et al., 2017) with an operationalisation of activities and skills needed that was missing before. The iterative specification, implementation and refinement of the ICT-enabled service were identified as part of the revision process for scaling in CIS. This iterative approach enables the identification of interdependences between the organisational context and ICT that is part of an ongoing discussion in literature (Storey et al., 2016; Troilo et al., 2017). The findings from this study demonstrate more clearly than previous research that an interplay of the personal and ICT-enabled processes allows limited scaling of CIS and advanced knowledge about design restrictions in ICT-enabled service innovations.

The insights on service validation demonstrate how services can be adapted more effectively to the requirements of customers in the service innovation process. Specifically, the 


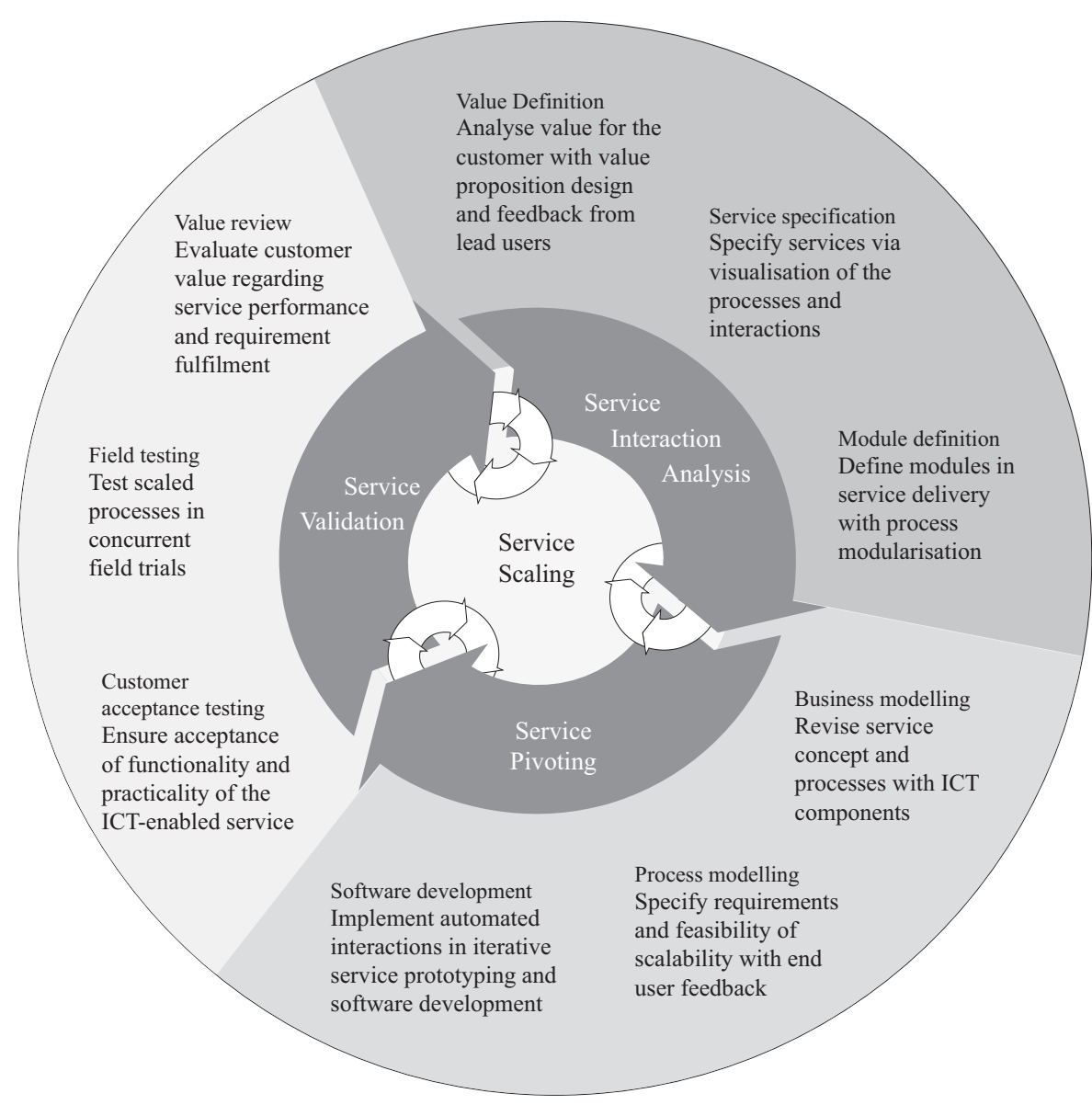

ICT-enabled service innovation

Figure 2.

Service scaling model including practices and activities

service validation practice illustrates that testing and evaluation of functionality, acceptance, usability and practicality are the core of customer feedback (Edvardsson et al., 2012; Russo-Spena and Mele, 2012). This validation of the service concept, the service processes and the customer experience give a desired integration of the key aspects in service innovation (Chew, 2016) and stand in contrast to the existing literature (Table I). The combination of validation with customer acceptance testing and the field testing creates the prerequisite for an acceptance in the value review by the project companies. The description of the practices explicates prototyping and feedback that were implicitly included in iterations with the customer and thus represents an extension of the literature.

\section{Implications for practice}

The findings reveal that the formative characteristic of personal interaction limit and determine the scalability of CIS. However, the service scaling practices of service interaction analysis, service pivoting and service validation allow a substantial enhancement of CIS offerings and service delivery that leverage the scaling opportunities within the limits of personal interaction in CIS. Therefore, the findings offer implications for practice. 
The practice of service interaction analysis reveals that an analysis and definition of the innovation object can be useful for finding effective service scaling approaches. In particular, the practice illustrates how companies can focus on scaling in CIS and in service innovations. Thereby, the visualisation of the service concept, service processes and ICT components promotes discussion and offers starting points for scaling services. A further breaking down of the CIS into modules can offer concrete starting points for scaling and innovation in a limited area that is relatively independent of the overall service. In summary, a simplification of the problem can be achieved using the practice of service interaction analysis.

The practice of service pivoting indicates that the augmentation and substitution of employees with ICT components has been a critical aspect of implementing service scaling. In organisations, the service scaling aspects are mostly restricted to digital services (such as Amazon Web Service), representing an early operationalisation of service scaling. However, the scaling practices and their activities offer concrete implementation approaches to transfer those desired properties of scalability to other areas. The step-by-step approach, from the modelling of the processes to the modelling of the overall service business and then to the software development, is a concrete and iterative approach that is accompanied by the customer. In summary, service companies can learn with the customer if the implementation of ICT components makes sense.

The practice of service validation offers guidance for acceptance of the scaling in CIS and the acceptance of service innovations by the customer and the employees. The activities in the practice of service validation reveal that performing several iterations can increase the coherence between service concept, service processes with ICT components and customer experience. Furthermore, the practice demonstrates the value of rapid feedback in the change of processes and structures. In summary, companies can rely on the impact of the actions taken in service scaling and service innovation, and thereby reduce the risk associated with service innovation.

\section{Limitations and further research}

This study and its methodology have their limitations. First, the aim of this study was to identify and describe practices used in scaling CIS. These practices should include detailed and complete descriptions of the "embodied, materially mediated arrays of human activity" (Schatzki, 2001, p. 11). The descriptions of the three practices for scaling CIS were detailed on the basis of the activities and enriched with examples. However, the completeness in these descriptions require a huge effort in the research process that are not proportional to the new knowledge obtained. Therefore, the data collection was focussed on practices that were observable in all three cases and made a substantial contribution to scaling CIS. Further research could enlarge this data collection to include even more details and new practices, and thereby attain more complete knowledge of the scaling practices.

Second, the practice lens offers a unique view of the individual activities in scaling CIS. This unique view contains ambiguities in seeing and interpreting the practices because service scaling is a complex phenomenon with different knowledge needed at different stages. The data collection and analysis was designed in such a way that the research is comprehensible and rigorous on the basis of the same structure. However, this data collection and analysis included project teams and researchers with experience with the involved services. The limitation in this setting therefore results from the strengths and views of the persons involved. Future research may challenge these views by adopting a different approach to CIS scaling.

Third, the case-based setting provided the possibility to investigate service scaling in the context of CIS. This setting gave a unique possiblity of data collection and analysis that enabled the specific findings. The main limitation of this study arises from the individuality 
of the cases. The findings in these specific settings cannot be directly extended to other companies with the same degree of certainty that quantitative analyses can. An example of this uncertainty is that commercialisation may be a part of service innovation, but the focus of the service innovation in the considered CIS was more on value creation for the customer. At the same level of detail, it is certainly not possible to assume generalisability on other points in the practices. Thus, a further quantitative confirmation of the findings could make greater generalisation possible.

\section{Conclusion}

The growing demand for personal services forces service providers to innovate and scale their CIS. However, knowledge about service scaling practices as an operationalisation of ICT-enabled service innovation was missing. Therefore, the objective of this study was to identify and describe how service providers achieve scalability of CIS (RQ of this study). Drawing on qualitative methods - including a practice-based approach, a case-based data collection as well as an interpretive and in-depth analysis - this study identifies for the first time three practices for scaling CIS: service interaction analysis, service pivoting and service validation. The descriptions of the corresponding activities for each practice from the cases detail the insights. Therefore, the practices offer contributions detailing the service innovation process, the role of ICT-enabled service innovation in scaling, and the adaption of the innovations. Service providers are thereby assisted with hands-on advice on how to approach scalability of CIS.

\section{Acknowledgements}

The research presented was partially funded by European Commission and the Swiss State Secretariat for Education, Research and Innovation (SERI) in the Active Assisted Living (AAL) programme under contract number AAL-2013-6-145 as well as by an International Postdoctoral Fellowship (project number 1031525) that was awarded to Christoph Peters by the University of St. Gallen's Basic Research Fund. The authors would like to thank the special issue editors and two anonymous reviewers for providing valuable comments on the manuscript.

\section{References}

Agarwal, R. and Selen, W. (2011), "Multi-dimensional nature of service innovation: operationalisation of the elevated service offerings construct in collaborative service organisations", International Journal of Operations \& Production Management, Vol. 31 No. 11, pp. 1164-1192.

Barras, R. (1986), "Towards a theory of innovation in services", Research Policy, Vol. 15 No. 4, pp. 161-173.

Barrett, M., Davidson, E., Prabhu, J. and Vargo, S.L. (2015), "Service innovation in the digital age: key contributions and future directions", MIS Quarterly, Vol. 39 No. 1, pp. 135-154.

Beverungen, D., Lüttenberg, H. and Wolf, V. (2018), "Recombinant service systems engineering", Business \& Information Systems Engineering, Vol. 60 No. 5, pp. 377-391.

Bitner, M.J., Ostrom, A.L. and Morgan, F.N. (2008), "Service blueprinting: a practical technique for service innovation", California Management Review, Vol. 50 No. 3, pp. 66-95.

Blomkvist, J. and Holmlid, S. (2010), "Service prototyping according to service design practitioners", Proceedings of the 2nd Service Design and Innovation Conference, Linköping, pp. 1-11.

Bondi, A.B. (2000), "Characteristics of scalability and their impact on performance", Proceedings of the Second International Workshop on Software and Performance, New York, NY, pp. 195-203.

Breidbach, C.F., Antons, D. and Salge, T.O. (2016), "Seamless service? On the role and impact of service orchestrators in human-centered service systems", Journal of Service Research, Vol. 19 No. 4, pp. 458-476. 
Buell, R.W. (2018), "The parts of customer service that should never be automated", Harvard Business Review, available at: https://hbr.org/2018/02/the-parts-of-customer-service-that-shouldnever-be-automated (accessed 21 August 2019).

Chase, R.B. (1981), "The customer contact approach to services: theoretical bases and practical extensions", Operations Research, Vol. 29 No. 4, pp. 698-706.

Chen, J.-S., Tai Tsou, H. and Huang, A.Y.-H. (2009), "Service delivery innovation: antecedents and impact on firm performance", Journal of Service Research, Vol. 12 No. 1, pp. 36-55.

Chen, S.-H., Wen, P.-C. and Yang, C.-K. (2014), "Business concepts of systemic service innovations in e-Healthcare", Technovation, Vol. 34 No. 9, pp. 513-524.

Chew, E.K. (2016), "iSIM: an integrated design method for commercializing service innovation", Information Systems Frontiers, Vol. 18 No. 3, pp. 457-478.

Deloitte (2017), "Global contact center survey", available at: www2.deloitte.com/us/en/pages/ operations/articles/global-contact-center-survey.html (accessed 21 August 2019).

den Hertog, P., van der Aa, W. and de Jong, M.W. (2010), "Capabilities for managing service innovation: towards a conceptual framework", Journal of Service Management, Vol. 21 No. 4, pp. 490-514.

Di Pietro, L., Edvardsson, B., Reynoso, J., Renzi, M.F., Toni, M. and Guglielmetti Mugion, R. (2018), “A scaling up framework for innovative service ecosystems: lessons from Eataly and KidZania", Journal of Service Management, Vol. 29 No. 1, pp. 146-175.

Droege, H., Hildebrand, D. and Heras Forcada, M.A. (2009), "Innovation in services: present findings, and future pathways", Journal of Service Management, Vol. 20 No. 2, pp. 131-155.

Edvardsson, B., Kristensson, P., Magnusson, P. and Sundström, E. (2012), "Customer integration within service development: a review of methods and an analysis of insitu and exsitu contributions", Technovation, Vol. 32 Nos 7/8, pp. 419-429.

Feldman, M.S. and Orlikowski, W.J. (2011), "Theorizing practice and practicing theory”, Organization Science, Vol. 22 No. 5, pp. 1240-1253.

Gibbert, M., Ruigrok, W. and Wicki, B. (2008), "What passes as a rigorous case study?”, Strategic Management Journal, Vol. 29 No. 13, pp. 1465-1474.

Gioia, D.A., Corley, K.G. and Hamilton, A.L. (2013), "Seeking qualitative rigor in inductive research: notes on the Gioia methodology”, Organizational Research Methods, Vol. 16 No. 1, pp. 15-31.

Glaser, B.G. and Strauss, A.L. (1999), The Discovery of Grounded Theory: Strategies for Qualitative Research, Routledge.

Glushko, R.J. and Nomorosa, K.J. (2012), "Substituting information for interaction: a framework for personalization in service encounters and service systems", Journal of Service Research, Vol. 16 No. 1, pp. 21-38.

Goldstein, S.M., Johnston, R., Duffy, J. and Rao, J. (2002), “The service concept: the missing link in service design research", Journal of Operations Management, Vol. 20 No. 2, pp. 121-134.

Helkkula, A., Kowalkowski, C. and Tronvoll, B. (2018), "Archetypes of service innovation”, Journal of Service Research, Vol. 21 No. 3, pp. 284-301.

Hill, M.D. (1990), "What is scalability?", ACM SIGARCH Computer Architecture News, Vol. 18 No. 4, pp. 18-21.

Huang, J., Henfridsson, O., Liu, M.J. and Newell, S. (2017), "Growing on steroids: rapidly scaling the user base of digital ventures through digital innovaton”, MIS Quarterly, Vol. 41 No. 1, pp. 301-314.

Jaakkola, E., Meiren, T., Witell, L., Edvardsson, B., Schäfer, A., Reynoso, J., Sebastiani, R. and Weitlaner, D. (2017), "Does one size fit all? New service development across different types of services", Journal of Service Management, Vol. 28 No. 2, pp. 329-347.

Jin Zhang, J., Lichtenstein, Y. and Gander, J. (2015), "Designing scalable digital business models", in Baden-Fuller, C. and Mangematin, V. (Eds), Business Models and Modelling, Vol. 33, Emerald, Bingley, pp. 241-277. 
Karlsson, J. and Skålén, P. (2015), "Exploring front-line employee contributions to service innovation”, European Journal of Marketing, Vol. 49 Nos 9/10, pp. 1346-1365.

Leimeister, J.M. (2014), Collaboration Engineering: IT-Gestützte Zusammenarbeitsprozesse systematisch entwickeln und durchführen, Gabler, Berlin.

Leimeister, J.M. (2019), Dienstleistungsengineering und -Management, 2nd ed., Springer, Berlin.

Lewis, M.O., Mathiassen, L. and Rai, A. (2011), "Scalable growth in IT-enabled service provisioning: a sensemaking perspective”, European Journal of Information Systems, Vol. 20 No. 3, pp. 285-302.

Lusch, R.F. and Nambisan, S. (2015), "Service innovation: a service-dominant-logic perspective”, MIS Quarterly, Vol. 39 No. 1, pp. 155-175.

Martelo Landroguez, S., Barroso Castro, C. and Cepeda-Carrión, G. (2013), "Developing an integrated vision of customer value”, Journal of Services Marketing, Vol. 27 No. 3, pp. 234-244.

Meiren, T. and Burger, T. (2010), “Testing of service concepts”, The Service Industries Journal, Vol. 30 No. 4, pp. 621-632.

Meuter, M.L., Ostrom, A.L., Roundtree, R.I. and Bitner, M.J. (2000), "Self-service technologies: understanding customer satisfaction with technology-based service encounters", Journal of Marketing, Vol. 64 No. 3, pp. 50-64.

Miles, M.B., Huberman, A.M. and Saldaña, J. (2014), Qualitative Data Analysis: A Methods Sourcebook, Sage Publications, Thousand Oaks, CA.

Möller, K., Rajala, R. and Westerlund, M. (2008), "Service innovation myopia?”, California Management Review, Vol. 50 No. 3, pp. 31-48.

Nambisan, S., Lyytinen, K., Majchrzak, A. and Song, M. (2017), "Digital innovation management: reinventing innovation management research in a digital world”, MIS Quarterly, Vol. 41 No. 1, pp. 223-238.

Nicolini, D. (2009), "Zooming in and out: studying practices by switching theoretical lenses and trailing connections”, Organization Studies, Vol. 30 No. 12, pp. 1391-1418.

Ojasalo, J. and Ojasalo, K. (2018), “Lean service innovation”, Service Science, Vol. 10 No. 1, pp. 25-39.

Orlikowski, W.J. (2000), "Using technology and constituting structures: a practice lens for studying technology in organizations”, Organization Science, Vol. 11 No. 4, pp. 404-428.

Osterwalder, A. and Pigneur, Y. (2010), Business Model Generation: A Handbook for Visionaries, Game Changers, and Challengers, John Wiley \& Sons, Hoboken, NJ.

Osterwalder, A., Pigneur, Y., Bernarda, G. and Smith, A. (2015), Value Proposition Design: How to Create Products and Services Customers Want, John Wiley \& Sons, Hoboken, NJ.

Papastathopoulou, P. and Hultink, E.J. (2012), "New service development: an analysis of 27 years of research”, Journal of Product Innovation Management, Vol. 29 No. 5, pp. 705-714.

Patrício, L., Fisk, R.P. and Falcão e Cunha, J. (2008), "Designing multi-interface service experiences", Journal of Service Research, Vol. 10 No. 4, pp. 318-334.

Patrício, L., Fisk, R.P., Falcão e Cunha, J. and Constantine, L. (2011), "Multilevel service design: from customer value constellation to service experience blueprinting", Journal of Service Research, Vol. 14 No. 2, pp. 180-200.

Payne, A., Frow, P. and Eggert, A. (2017), "The customer value proposition: evolution, development, and application in marketing", Journal of the Academy of Marketing Science, Vol. 45 No. 4, pp. 467-489.

Reckwitz, A. (2002), "Toward a theory of social practices", European Journal of Social Theory, Vol. 5 No. 2, pp. 243-263.

Ries, E. (2011), The Lean Startup: How Today's Entrepreneurs Use Continuous Innovation to Create Radically Successful Businesses, Crown Publishing, New York, NY.

Russo-Spena, T. and Mele, C. (2012), “'Five Co-s' in innovating: a practice-based view”, Journal of Service Management, Vol. 23 No. 4, pp. 527-553.

Schatzki, T.R. (2001), "Introduction: practice theory", in Schatzki, T.R., Cetina, K.K. and von Savigny, E. (Eds), The Practice Turn in Contemporary Theory, Routledge, London, pp. 10-23.
ICT-enabled service innovation 
Skålén, P., Gummerus, J., von Koskull, C. and Magnusson, P.R. (2015), "Exploring value propositions and service innovation: a service-dominant logic study", Journal of the Academy of Marketing Science, Vol. 43 No. 2, pp. 137-158.

Storey, C., Cankurtaran, P., Papastathopoulou, P. and Hultink, E.J. (2016), "Success factors for service innovation: a meta-analysis", Journal of Product Innovation Management, Vol. 33 No. 5 , pp. 527-548.

Täuscher, K. and Abdelkafi, N. (2018), "Scalability and robustness of business models for sustainability: a simulation experiment”, Journal of Cleaner Production, Vol. 170, pp. 654-664, available at: www.sciencedirect.com/science/article/pii/S0959652617320115

Teixeira, J., Patrício, L., Huang, K.-H., Fisk, R.P., Nóbrega, L. and Constantine, L. (2017), "The MINDS method: integrating management and interaction design perspectives for service design", Journal of Service Research, Vol. 20 No. 3, pp. 240-258.

Teixeira, J.G., Patrício, L., Nunes, N.J., Nóbrega, L., Fisk, R.P. and Constantine, L. (2012), “Customer experience modeling: from customer experience to service design", Journal of Service Management, Vol. 23 No. 3, pp. 362-376.

Troilo, G., De Luca, L.M. and Guenzi, P. (2017), "Linking data-rich environments with service innovation in incumbent firms: a conceptual framework and research propositions", Journal of Product Innovation Management, Vol. 34 No. 5, pp. 617-639.

van Alstyne, M.W., Parker, G.G. and Choudary, S.P. (2016), "Pipelines, platforms, and the new rules of strategy: scale now trumps differentiation", Harvard Business Review, Vol. 94 No. 4, pp. 54-63.

Vargo, S.L. and Lusch, R.F. (2016), "Institutions and axioms: an extension and update of servicedominant logic", Journal of the Academy of Marketing Science, Vol. 44 No. 1, pp. 5-23.

von Hippel, E. (1986), "Lead users: a source of novel product concepts", Management Science, Vol. 32 No. 7, pp. 791-805.

Voss, C.A. and Hsuan, J. (2009), "Service architecture and modularity”, Decision Sciences, Vol. 40 No. 3, pp. 541-569.

Walsham, G. (1995), "Interpretive case studies in IS research: nature and method", European Journal of Information Systems, Vol. 4 No. 2, pp. 74-81.

Walsham, G. (2006), "Doing interpretive research”, European Journal of Information Systems, Vol. 15 No. 3, pp. 320-330.

Witell, L., Snyder, H., Gustafsson, A., Fombelle, P. and Kristensson, P. (2016), "Defining service innovation: a review and synthesis", Journal of Business Research, Vol. 69 No. 8, pp. 2863-2872.

Witell, L., Gebauer, H., Jaakkola, E., Hammedi, W., Patricio, L. and Perks, H. (2017), "A bricolage perspective on service innovation”, Journal of Business Research, Vol. 79, pp. 290-298, available at: www.sciencedirect.com/science/article/abs/pii/S0148296317301091

Wooder, S. and Baker, S. (2012), "Extracting key lessons in service innovation", Journal of Product Innovation Management, Vol. 29 No. 1, pp. 13-20.

Yu, E. and Sangiorgi, D. (2018), "Service design as an approach to implement the value cocreation perspective in new service development", Journal of Service Research, Vol. 21 No. 1, pp. 40-58.

Zhao, Y.L. and Di Benedetto, C.A. (2013), "Designing service quality to survive: empirical evidence from Chinese new ventures”, Journal of Business Research, Vol. 66 No. 8, pp. 1098-1107.

\section{Corresponding author}

Stefan Kleinschmidt can be contacted at: stefan.kleinschmidt@unisg.ch

For instructions on how to order reprints of this article, please visit our website:

www.emeraldgrouppublishing.com/licensing/reprints.htm

Or contact us for further details: permissions@emeraldinsight.com 